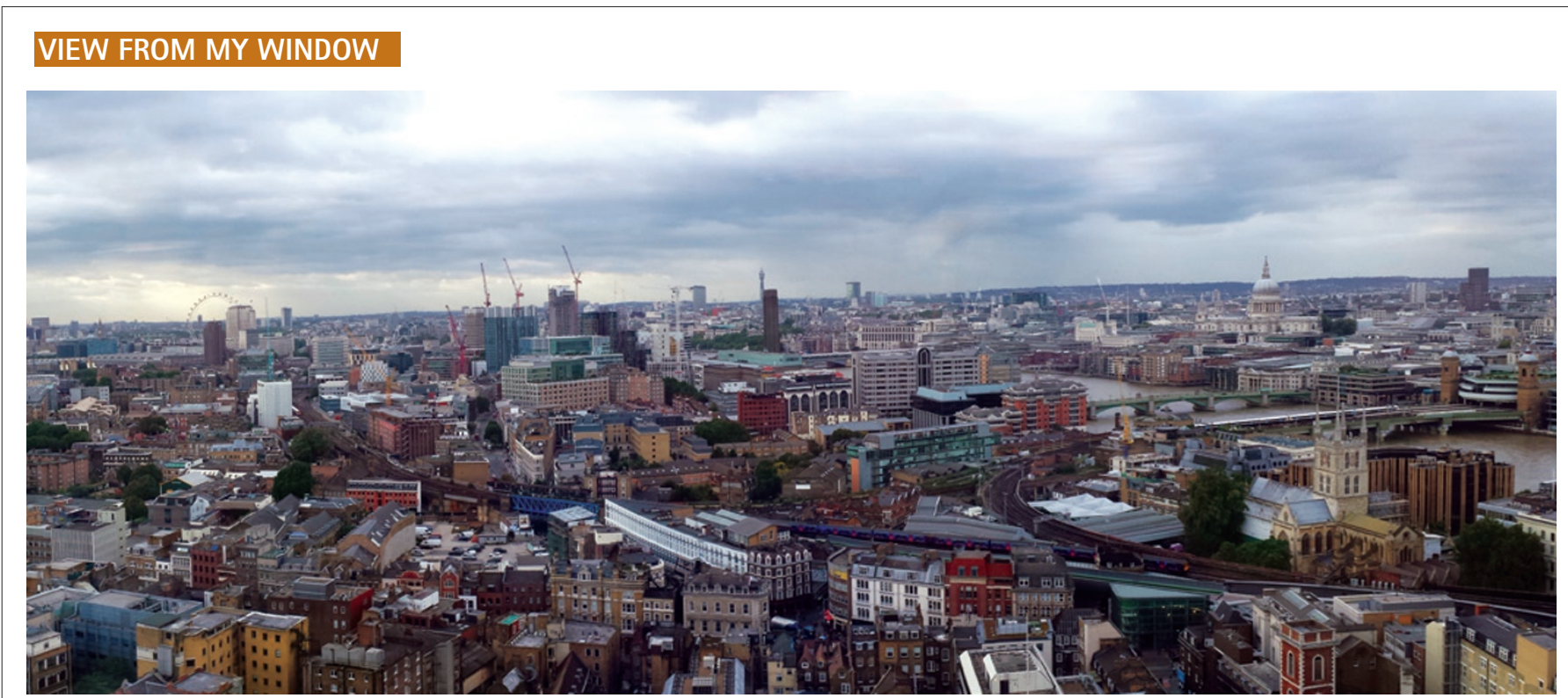

Tim Rankin, GDP and part time clinical teacher at Guy's Hospital Dental Institute, sent in this impressive view from the Shard Dental Clinic on the 21st floor of Guy's Hospital Tower overlooking the Thames and the City of London.

To submit the view from your window, email k.quinlan@nature.com.

\section{CLARION CALL TO DENTISTS}

The Chair of the General Dental Council (GDC), Bill Moyes, used the Faculty of General Dental Practice (UK)'s biennial Malcolm Pendlebury Memorial Lecture in June to urge the dental profession to seek better ways to resolve patient complaints.

His comments come on the back of a $110 \%$ increase in complaints received by the GDC in the last four years, and costs related to fitness to practise cases accounting for more than half of the regulator's budget. In 2012-2013, NHS England, the Dental Complaints Service, the Care Quality Commission, and the GDC collectively received in excess of 13,000 complaints, which Mr Moyes described as 'staggeringly high'. He called for stakeholders to continue the momentum towards regulatory reform in light of the Government's decision not to progress the Law Commission's draft Bill on a single legal framework for the regulation of health and social care professionals.

Trevor Ferguson, Dean of the FGDP(UK), said that Mr Moyes' concerns could be considered a 'clarion call to the profession'.

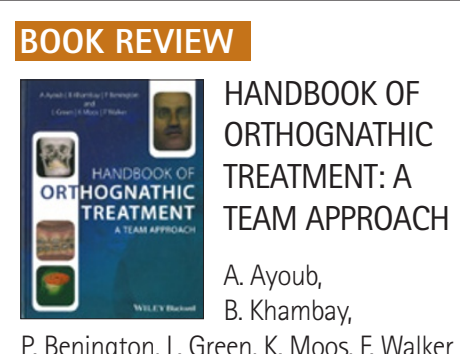

P. Benington, L. Green, K. Moos, F. Walker Wiley Blackwell

price Ł49.99; pp 194

ISBN 9780470659052

Written by a multidisciplinary team mainly based in Glasgow, this book is intended for trainees new to the world of orthognathic surgery, although clinicians of all levels will find a chapter of interest to them.

Intended learning outcome boxes are provided at the start of every chapter. It is written in such a way that all relevant aspects are covered in a concise systematic manner.

This is one of those few books that dedicate a great appreciation to the psychological aspects of facial deformity including its impact on patients' lives and their expectations. In the opening chapter, the authors cleverly divide the psychological problems into a red, amber and green flag system. This chapter reinforces the need for psychological consideration in the more extreme cases, which is often ignored.

The chapter entitled 'Dentofacial assessment' is suitably written and very well complimented by coloured diagrams and photographs. Most orthodontic textbooks shy away from describing the use of face bows and articulators in relation to orthognatic treatment planning at such a basic level. However, it is refreshing to see that the fifth chapter illustrates not just their contributions but also highlights the inherent errors occurring with their use.

Currently most surgeons use lateral cephalographs and study models to plan surgery. Nonetheless, Chapter six focuses on the innovative technological methods used in routine surgical planning, including 3D cone beam CT programmes and stereophotogrammetry. The authors acknowledge that the more advanced and modern surgical techniques described do not represent a definitive guide for treating highly complex cases.

Logical step-by-step descriptions of the surgeries are briefly described. The excellent use of imagery once again allows the reader to visualise what is otherwise regarded as complicated procedures.

The book concludes with six different case reports. I found that the information described in each chapter was consolidated into a succinct description of each case from start to finish. The concept of an interdisciplinary team approach is once again reinforced.

This is a great introductory book for maxillofacial surgery senior house officers in particular. At a time when computer software is becoming pertinent clinically and emphasis on psychological aspects of healthcare is growing, this book succeeds in updating our basic knowledge.

F. PATEL 